\title{
Predictors of distress in female breast cancer survivors: a systematic review
}

\author{
Ania Syrowatka $^{1,2}$ (10) Aude Motulsky ${ }^{1,3} \cdot$ Siyana Kurteva $^{1,2} \cdot$ James A. Hanley $^{2,4}$. \\ William G. Dixon ${ }^{5,6} \cdot$ Ari N. Meguerditchian ${ }^{1,7,8} \cdot$ Robyn Tamblyn ${ }^{1,2,9}$
}

Received: 10 January 2017 / Accepted: 10 May 2017/Published online: 28 May 2017

(C) The Author(s) 2017. This article is an open access publication

\begin{abstract}
Purpose Unmanaged distress has been shown to adversely affect survival and quality of life in breast cancer survivors. Fortunately, distress can be managed and even prevented with appropriate evidence-based interventions. Therefore, the objective of this systematic review was to synthesize the published literature around predictors of distress in female breast cancer survivors to help guide targeted intervention to prevent distress.

Methods Relevant studies were located by searching MEDLINE, Embase, PsycINFO, and CINAHL databases. Significance and directionality of associations for commonly assessed candidate predictors $(n \geq 5)$ and predictors shown to be significant $(p \leq 0.05)$ by at least two studies were summarized descriptively. Predictors were evaluated based on the proportion of studies that showed a significant and positive association with the presence of distress.
\end{abstract}

Electronic supplementary material The online version of this article (doi:10.1007/s10549-017-4290-9) contains supplementary material, which is available to authorized users.

Ania Syrowatka

anna.syrowatka@mail.mcgill.ca

1 Clinical and Health Informatics Research Group, McGill University, Montreal, QC, Canada

2 Department of Epidemiology, Biostatistics and Occupational Health, McGill University, Montreal, QC, Canada

3 Centre de recherche du Centre hospitalier de l'Université de Montréal, Montreal, QC, Canada

4 Department of Mathematics and Statistics, McGill University, Montreal, QC, Canada

5 Arthritis Research UK Centre for Epidemiology, Manchester Academic Health Sciences Centre, The University of Manchester, Manchester, UK
Results Forty-two studies met the target criteria and were included in the review. Breast cancer and treatment-related predictors were more advanced cancer at diagnosis, treatment with chemotherapy, longer primary treatment duration, more recent transition into survivorship, and breast cancer recurrence. Manageable treatment-related symptoms associated with distress included menopausal/vasomotor symptoms, pain, fatigue, and sleep disturbance. Sociodemographic characteristics that increased the risk of distress were younger age, non-Caucasian ethnicity, being unmarried, and lower socioeconomic status. Comorbidities, history of mental health problems, and perceived functioning limitations were also associated. Modifiable predictors of distress were lower physical activity, lower social support, and cigarette smoking.

Conclusions This review established a set of evidencebased predictors that can be used to help identify women at higher risk of experiencing distress following completion of primary breast cancer treatment.

6 Health eResearch Centre, Farr Institute, Manchester Academic Health Sciences Centre, The University of Manchester, Manchester, UK

7 Department of Surgery, McGill University Health Centre, Montreal, QC, Canada

8 Department of Oncology, McGill University Health Centre, Montreal, QC, Canada

9 Department of Medicine, McGill University, Montreal, QC, Canada 
Keywords Breast cancer - Survivorship - Predictor . Distress · Systematic review

\section{Introduction}

Around 1.67 million new cases of breast cancer were diagnosed worldwide in 2012, accounting for an estimated $25 \%$ of new cancer cases in women [1]. Earlier detection of breast tumors through screening mammography in combination with better and more targeted therapies has dramatically improved survival [2]. Medical advances have generated a large cohort of women surviving after completion of primary breast cancer treatment.

Current 5 and 10-year survival rates following breast cancer diagnosis are 87 and $82 \%$, respectively [3]. As a result, both clinicians and researchers are now focusing more efforts on improving quality of life and patient-centered outcomes in survivorship. The National Comprehensive Cancer Network (NCCN) has recognized distress as an important sequela of cancer diagnosis and treatment [4]. Formally, cancer-related distress is defined as "a multifactorial unpleasant emotional experience of a psychological (i.e., cognitive, behavioral, emotional), social, and/or spiritual nature that may interfere with the ability to cope effectively with cancer, its physical symptoms, and its treatment. Distress extends along a continuum, ranging from common normal feelings of vulnerability, sadness, and fears to problems that can become disabling, such as depression, anxiety, panic, social isolation, and existential and spiritual crises" [4]. Unmanaged distress has been shown to negatively impact all-cause and cancer-related morbidity and mortality, as well as quality of life [5].

Identification of distress during survivorship still presents a challenge; it may be unclear when normal feelings of vulnerability, sadness, and fears transition to a point requiring intervention or support. To address this issue, cancer care agencies have recommended that cancer patients be routinely screened for distress at appropriate intervals throughout primary treatment and survivorship, and at important clinical time points including remission, recurrence, progression, and treatment-related complications [4]. However, approximately $37 \%$ of breast cancer patients who have transitioned into survivorship will attend two or fewer follow-up visits with an oncologist within the first year following completion of primary treatment [6], limiting the number of opportunities for distress screening and potentially delaying necessary treatment.

An alternative approach could be to identify breast cancer patients at increased risk of developing distress following transition into survivorship. This would allow for targeted intervention to prevent distress, as well as enhanced monitoring to identify prodromal symptoms and early warning signs of distress for timely intervention to mitigate the risk of progression to diagnosable mental health problems. For example, intervention with prophylactic cognitive behavioral therapy (CBT) has been shown to reduce incidence of depression and anxiety in higher-risk cancer patients by half [7]. As a first step in this direction, the objective of this systematic review is to summarize the published literature around predictors of distress in breast cancer survivors.

\section{Methods}

\section{Study selection}

\section{Search strategy}

Four databases (MEDLINE, Embase, PsycINFO, and CINAHL) were searched for relevant studies published between January 1, 2000 and March 10, 2016. Studies published prior to the year 2000 were excluded since they were not considered to be representative of the current state of distress literature, given significant improvements in breast cancer treatments and survival rates, and increased awareness of mental health challenges in survivorship. Four main concepts of breast cancer, survivorship, predictor, and distress were mapped to the most relevant controlled vocabulary using Medical Subject Headings (MeSH), and free-text terms were added where necessary. Full search strategies are provided in Appendix 1 in electronic supplementary material.

\section{Inclusion and exclusion criteria}

This systematic review identified studies that measured the presence of distress (via clinical interviews, or distress scales) and evaluated potential predictors of presence of distress in female breast cancer patients who had completed primary treatment (i.e., surgery, chemotherapy, and/ or radiotherapy). Therefore, only studies that dichotomized the outcome as the presence or absence of distress were included in the review; articles that used a continuous outcome (e.g., total score on a distress scale) were not included. Distress was broadly defined based on specific mental health diagnoses (i.e., depressive disorders, anxiety disorders, obsessive-compulsive and related disorders, and trauma- and stressor-related disorders), as well as nonspecific symptoms (e.g., 'psychological,' 'psychosocial,' 'stress,' and 'distress'). All study designs were considered (e.g., cross-sectional, prospective cohort, etc.). Studies were excluded if the article did not report original research, or was not published in the English language. 


\section{Screening and data abstraction}

Screening of articles was completed in two stages. First, articles were screened for relevance based on information provided in the title and abstract, and subsequently evaluated for inclusion based on the full text. Two reviewers independently screened articles at each stage (title and abstract: AS and AM; full text: AS and SK). All articles considered eligible for inclusion by at least one reviewer based on the title and abstract screen were submitted for full-text review. Disagreements at the full-text screen were resolved by discussion and consensus between the two reviewers. Kappa scores were calculated to assess interrater reliability. Reference lists of eligible articles were searched to identify additional relevant studies for inclusion in the review.

One reviewer completed data abstraction (AS), which focused on citation information, study design, sample size and patient characteristics, type and prevalence of distress, measurement of distress (i.e., case ascertainment), timing of measurement, and predictors of distress (all predictors evaluated, and predictors significant in univariate and/or multivariate analyses). A second reviewer (SK) checked data abstracted from ten percent of the articles to assess quality of data abstraction, and one omission was identified.

\section{Evaluation of predictors}

Substantial heterogeneity in the formats of predictors (e.g., continuous, or not comparable classification approaches) limited the feasibility of meta-analysis to quantitatively synthesize results on the strength of association between predictors and the presence of distress. Consequently, significance and directionality of associations (i.e., positive, negative, or inconsistent/unspecified) for the most commonly assessed candidate predictors $(n \geq 5)$ as well as predictors shown to be significant $(p \leq 0.05)$ by at least two studies were summarized descriptively. Predictors were evaluated based on the proportion of studies that showed a significant and positive association (in univariate and/or multivariate analyses) with the presence of distress, in an effort to identify patterns to inform future research.

\section{Results}

\section{Study selection}

The search identified 2706 unique articles. The title and abstract screen retained 313 articles. Full-text screening with reference list searching identified 42 studies that met the target criteria and were included in the review. The kappa scores for title and abstract screen, and full-text screen were 0.43 and 0.54 , respectively, indicating 'moderate' agreement [8]. The moderate kappa scores reflect the complexity around defining distress and uncertainty around the beginning of the breast cancer survivorship period, as well as consideration of studies that did not focus specifically on breast cancer. A modified Preferred Reporting Items for Systematic Reviews and Meta-Analyses (PRISMA) flowchart is presented in Fig. 1 [9].

Characteristics of studies identified through the systematic review are presented in Table 1 [10-51]. Studies were published between 2001 and 2016, and were conducted in North America (19/42 studies; 45\%), Asia (12/42 studies; 29\%), and Europe (11/42 studies; 26\%). Half of the studies collected data using a prospective cohort (21/42 studies; $50 \%$ ), and the other half used a cross-sectional design (20/42 studies; $48 \%$ ) or retrospective chart review (1/42 studies; 2\%). Eight (8/21 studies; $38 \%$ ) of the prospective cohort studies reported distress trajectories, which describe how individual women's distress can change over time from diagnosis through primary treatment and into survivorship. The remaining studies reported prevalence of distress within the survivorship period, without describing how individual women's distress changes over time.

The majority of studies measured depression (30/42 studies; 71\%); anxiety, posttraumatic stress disorder (PTSD), general distress, and suicidal ideation were measured by 29\% (12/42 studies), 7\% (3/42 studies), 21\% (9/42 studies), and $2 \%$ (1/42 studies) of studies, respectively. The median prevalence of distress was $26 \%$ (interquartile range $39-17=22 \%$ ). The majority of studies assessed the presence of distress using validated cut-offs of the Center for Epidemiologic Studies-Depression scale (CES-D: 12/42 studies; 29\%) or the Hospital Anxiety and Depression Scale (HADS: 12/42 studies; 29\%). Timing of distress assessment in survivorship varied substantially. Eleven studies $(26 \%)$ evaluated distress in survivorship at a specific time point following breast cancer diagnosis (ranging from 1 to 4 years). The majority of studies based on distress trajectories (7/8 studies; $88 \%$ ) followed women for periods ranging from 1 to 2 years starting from breast cancer diagnosis. The remaining studies included survivors with varying times since breast cancer diagnosis, ranging from a mean of 17.6 months following breast surgery (standard deviation (SD): 9.0 months; range 6-36 months) to 10.5 years (range 5-32 years) following breast cancer diagnosis.

\section{Evaluation of predictors}

The significance and directionality of commonly assessed candidate predictors $(n \geq 5)$, as well as predictors shown to 


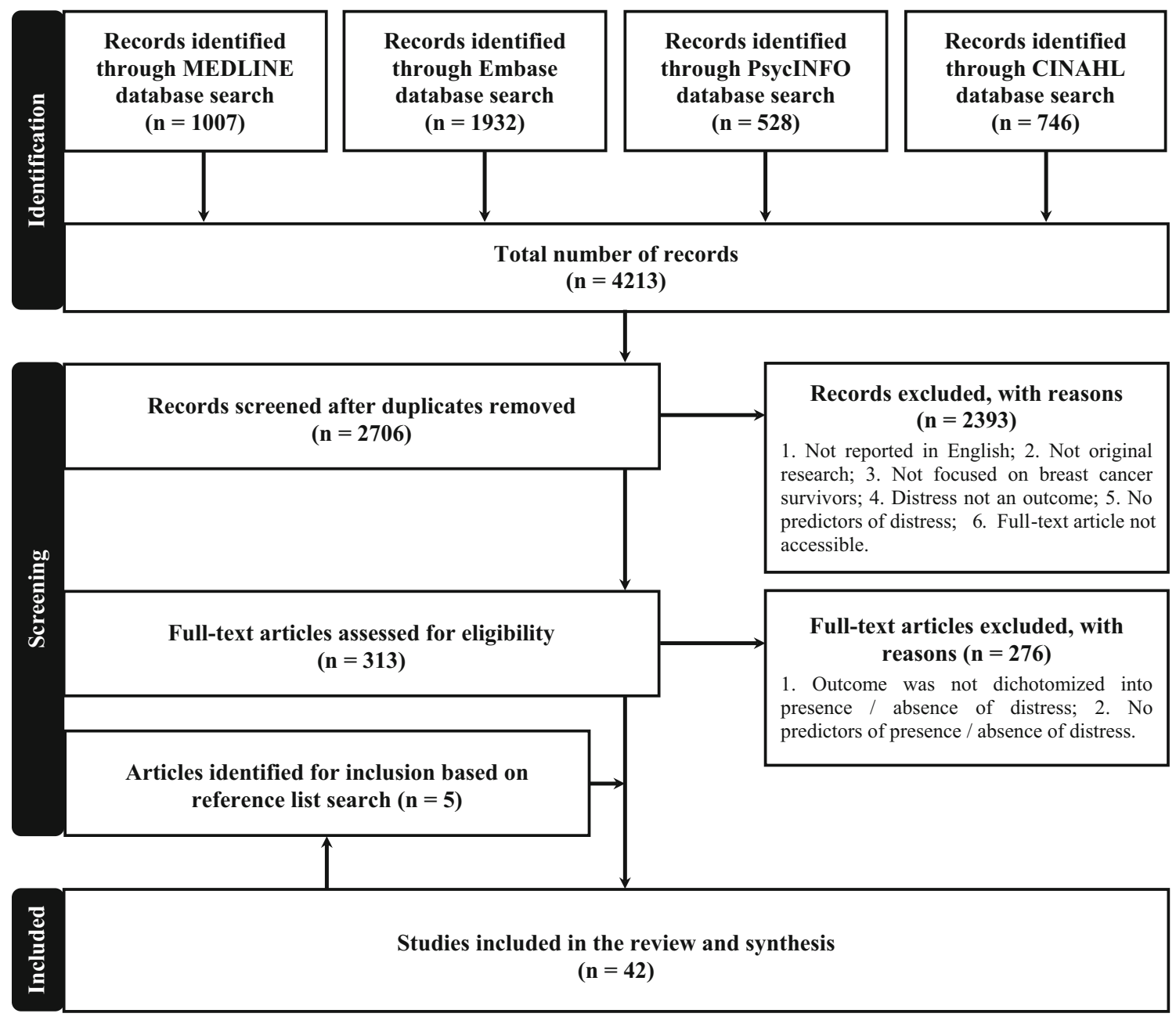

Fig. 1 PRISMA study selection flowchart

be significant $(p \leq 0.05)$ by at least two studies are summarized in Table 2 [10-23, 25, 27-33, 35-50], and categorized based on type of predictor: sociodemographic characteristics, breast cancer characteristics and treatment, treatment-related symptoms, comorbidities and medical history, perceived functioning limitations, and behavioral and support factors. All predictors evaluated within each study, alongside predictors shown to be significant $(p \leq 0.05)$ in univariate and multivariate analyses are presented in Appendix 2 in electronic supplementary material [10-51]. Twenty-eight of the 42 studies (67\%) reported on multivariate analyses conducted to estimate independent associations between candidate predictors and the presence of distress in breast cancer survivors; the remaining studies only reported data for univariate associations. Overall, studies that employed a cross-sectional design had larger sample sizes (mean: 560 women vs. 399 women for cohort and chart review studies) and were more likely to report significant associations between candidate predictors and distress.
The most commonly evaluated predictors were patient sociodemographic characteristics, breast cancer characteristics, and treatments. Sociodemographic characteristics that were associated with distress included: younger age (10/27 studies; $37 \%)$, non-Caucasian ethnicity (2/11 studies; $18 \%$ ), and being unmarried ( $8 / 23$ studies; $35 \%$ ). Lower socioeconomic status (SES) also increased the risk of distress including: lower education (3/21 studies; $14 \%)$, lower income (4/7 studies; 57\%), and experiencing financial difficulties (5/6 studies; 83\%). However, unemployment did not influence the risk of distress.

Breast cancer characteristics and treatments predictive of distress were more advanced cancer at diagnosis $(3 / 21$ studies; $14 \%)$, treatment with chemotherapy (4/18 studies; $22 \%)$, and longer primary treatment duration ( $2 / 2$ studies). However, type of breast surgery, treatment with radiotherapy, and treatment with hormone therapy did not influence the risk of distress. More recent transition into survivorship (3/10 studies; $30 \%$ ), and breast cancer recurrence (2/4 studies; $50 \%)$ were associated with distress. 


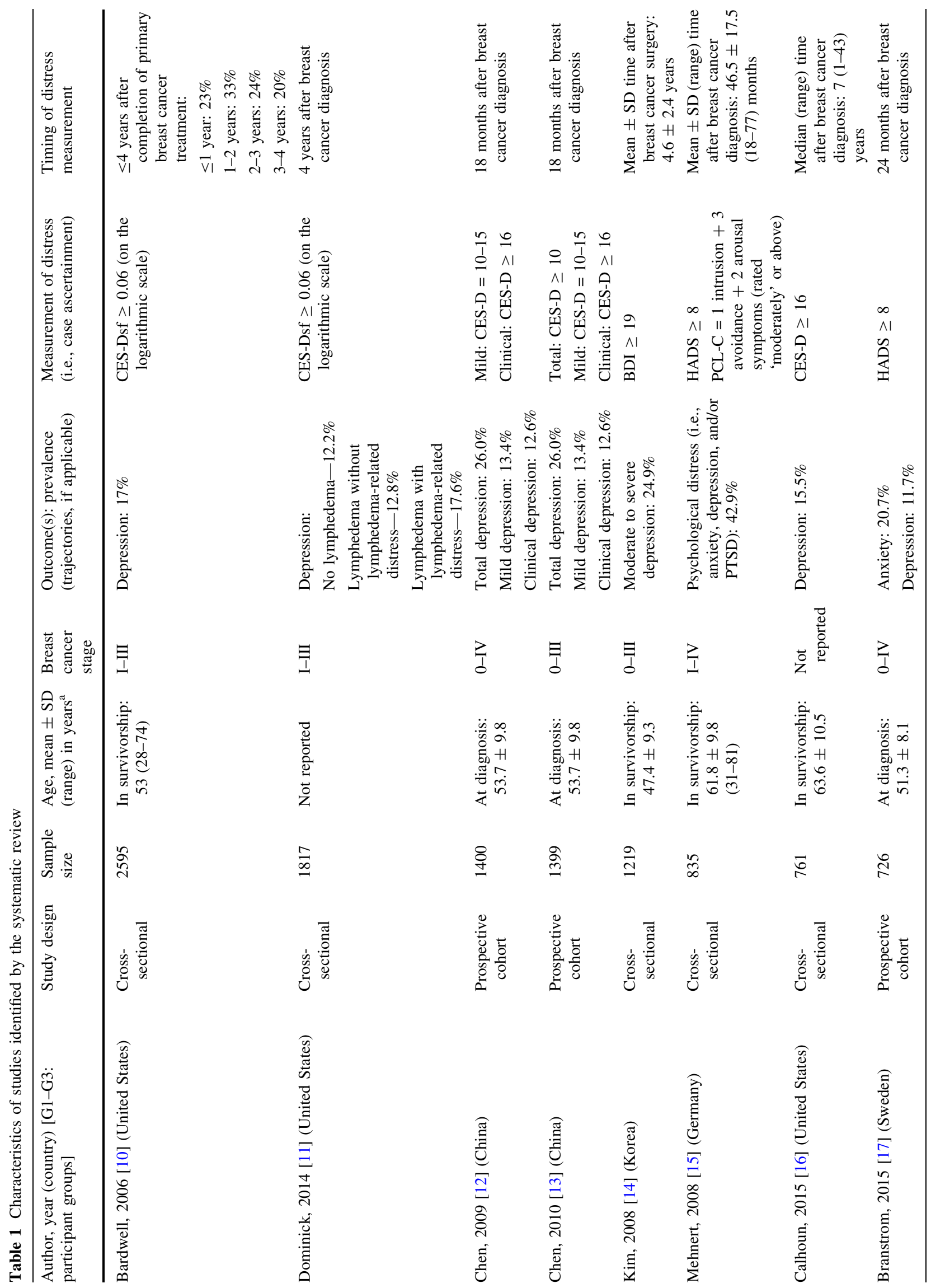




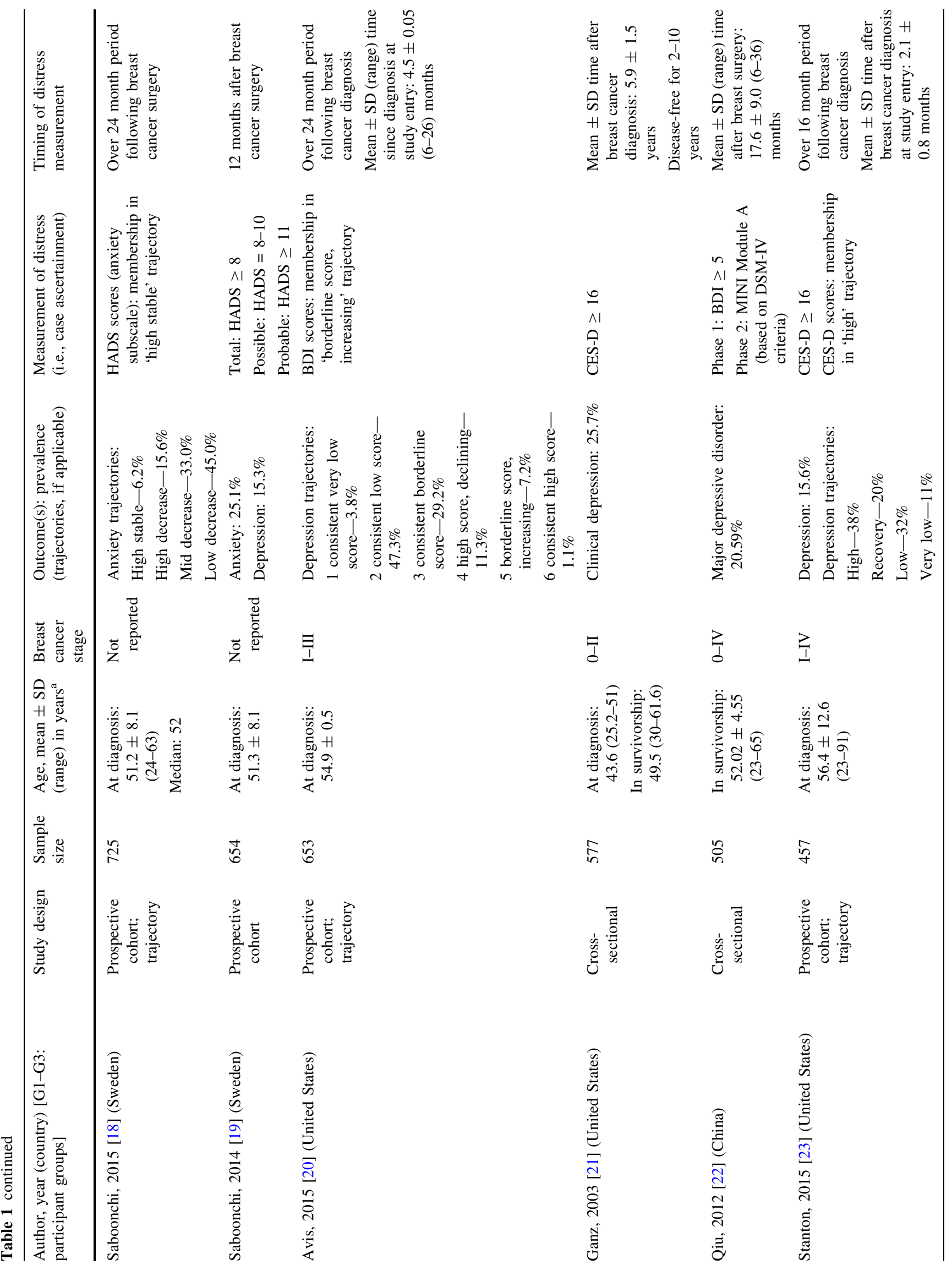




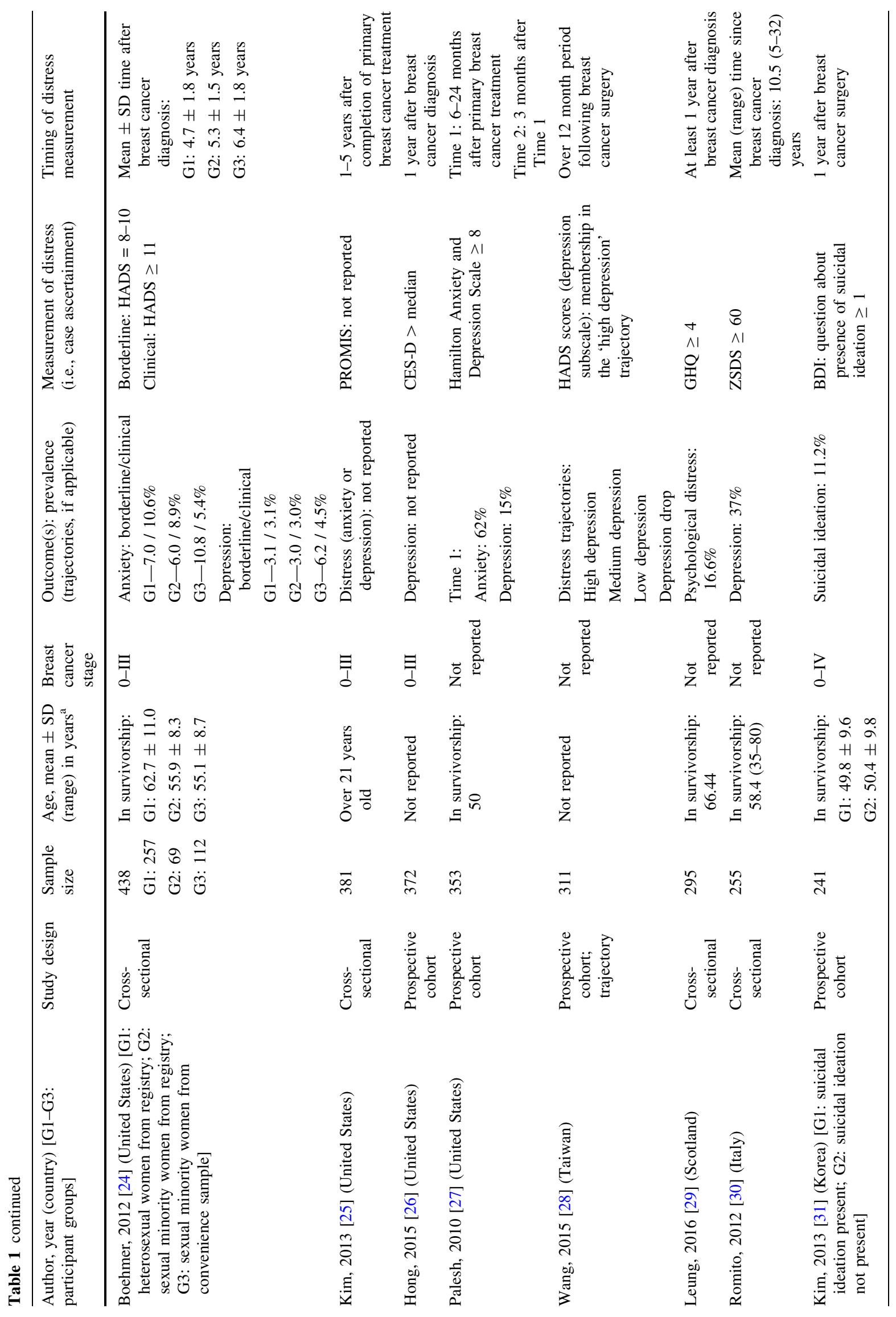




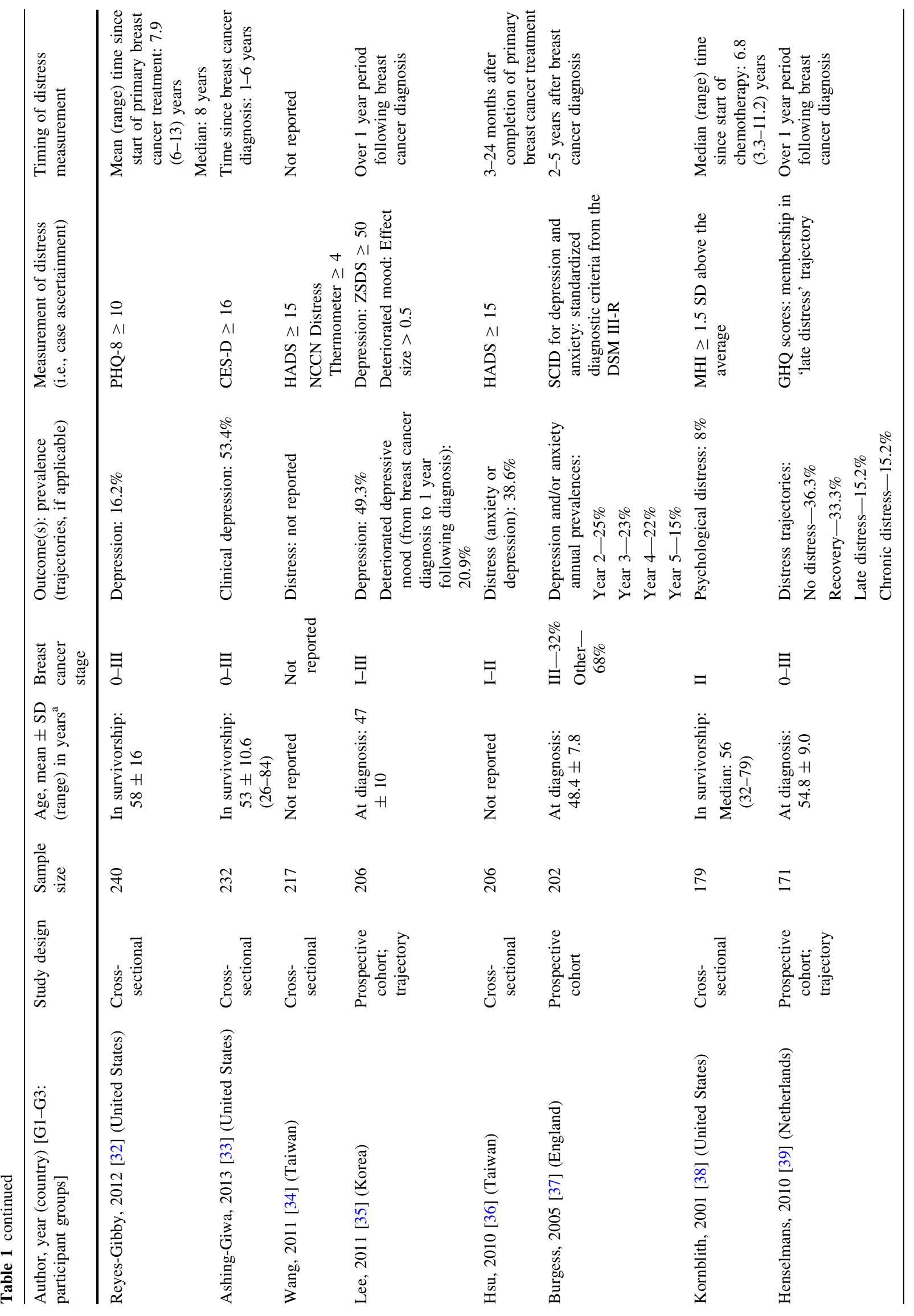




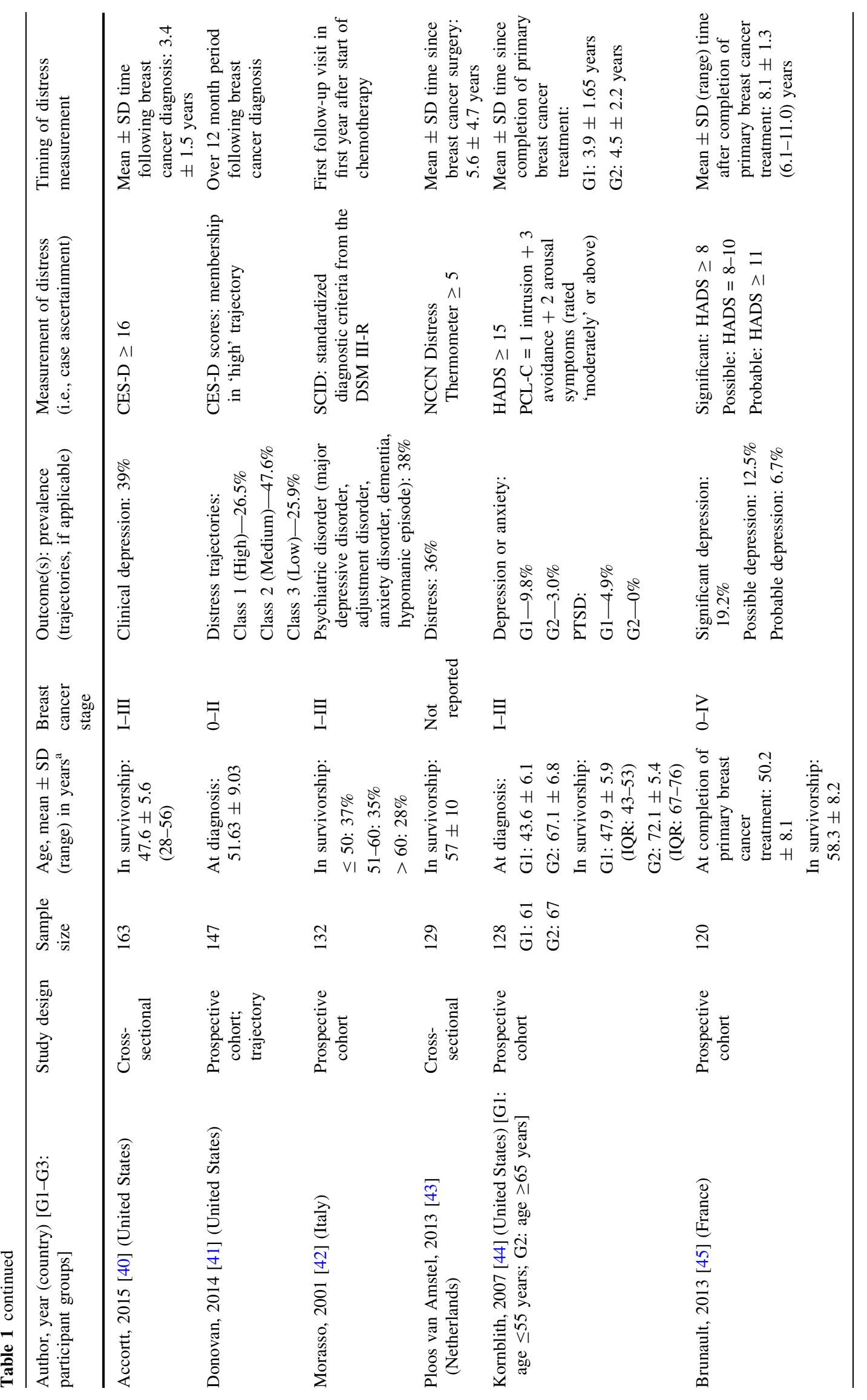




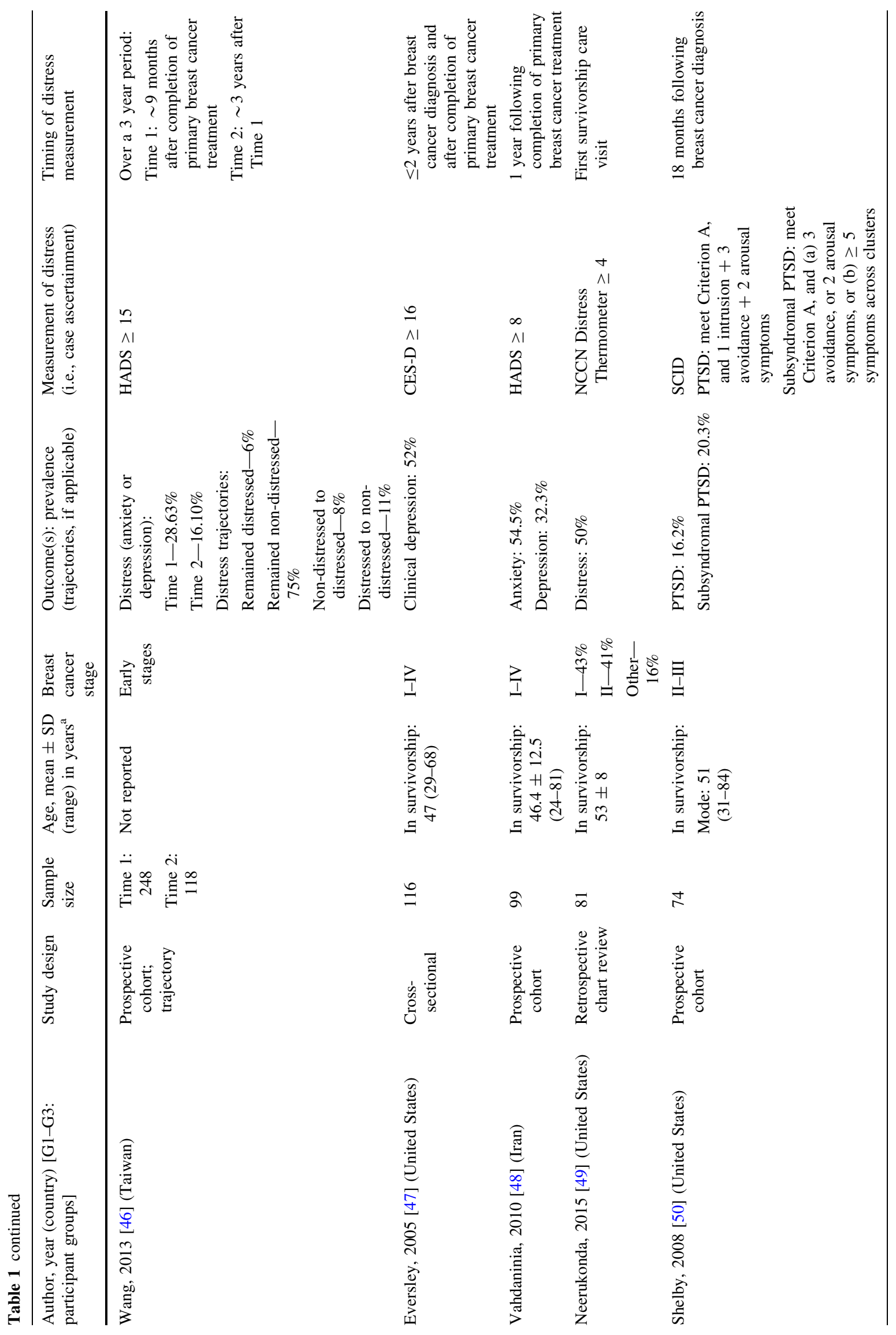




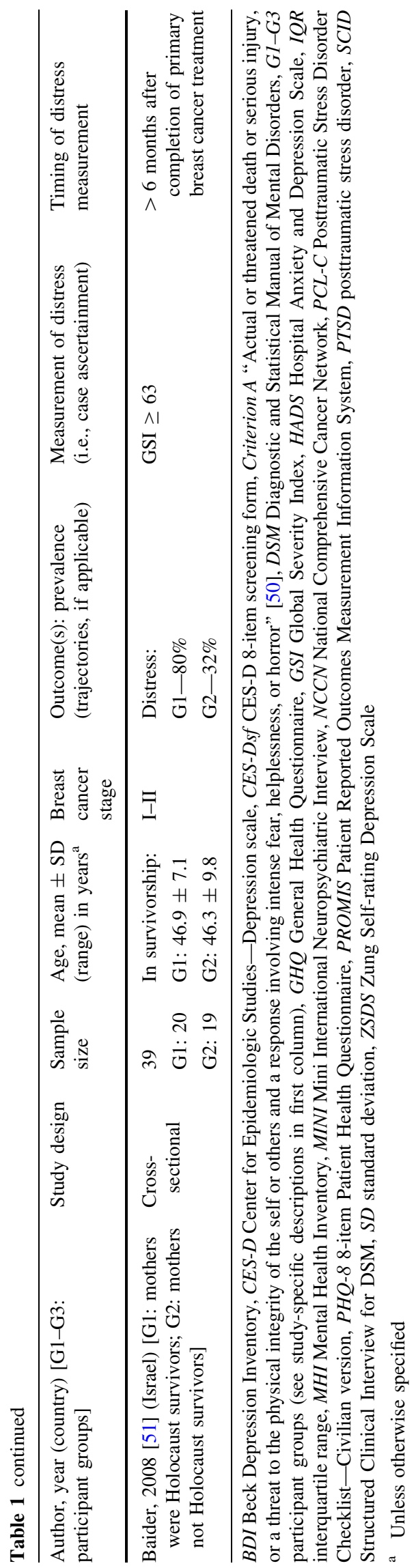

The following treatment-related symptoms were associated with distress: menopausal/vasomotor symptoms (7/ 10 studies; $70 \%)$, pain (9/12 studies; $75 \%)$, fatigue $(6 / 9$ studies; 67\%), sleep disturbance (7/9 studies; 78\%), lymphedema/arm symptoms (2/5 studies; $40 \%)$, breast symptoms (2/3 studies; $67 \%$ ), appetite loss (2/5 studies; $40 \%)$, diarrhea (3/5 studies; 60\%), and dyspnea (2/4 studies; $50 \%$ ). Constipation, nausea, and vomiting did not influence the risk of distress. Furthermore, higher number of treatment-related complaints (3/5 studies; 60\%) was associated with distress. Similarly, higher number of comorbidities (5/ 9 studies; $56 \%)$ and history of mental health problems (7/7 studies) increased the risk of distress.

Lower overall quality of life (6/8 studies; $75 \%$ ) and the following subscales/domains were associated with distress: lower quality of physical health (4/4 studies), lower quality of mental health (2/2 studies), physical functioning limitations $(6 / 8$ studies; $75 \%)$, role functioning limitations $(6 / 8$ studies; 75\%), emotional functioning limitations $(3 / 5$ studies; $60 \%$ ), cognitive functioning limitations (2/4 studies; $50 \%$ ), and social functioning limitations (4/6 studies; $67 \%$ ). Lower optimism (2/3 studies; 67\%), lower posttraumatic growth (3/3 studies), and higher number of stressful life events (3/6 studies; $50 \%$ ) also increased the risk of distress. In terms of behavioral and support factors, lower physical activity (5/8 studies; 63\%), lower social support (6/8 studies; $75 \%$ ), and cigarette smoking (2/6 studies; $33 \%$ ) were associated with distress, whereas higher alcohol intake and higher body mass index (BMI) did not influence the risk of distress.

\section{Discussion}

This systematic review is the first synthesis of the published literature around predictors of distress in female breast cancer patients who have completed primary treatment. Breast cancer and treatment-related predictors included more advanced cancer at diagnosis, treatment with chemotherapy, longer primary treatment duration, more recent transition into survivorship, and breast cancer recurrence. Treatment-related symptoms also increased the risk of distress including menopausal/vasomotor symptoms, pain, fatigue, and sleep disturbance. A variety of factors not specific to breast cancer survivors predicted distress. Associated sociodemographic characteristics were younger age, non-Caucasian ethnicity, being unmarried, and indicators of lower SES (specifically, lower education or income, and experiencing financial difficulties). Higher number of comorbidities and history of mental health problems also increased the risk of distress. Furthermore, lower quality of life, optimism, and posttraumatic growth, as well as higher number of stressful life events predicted 
Table 2 Significance and directionality of commonly assessed candidate predictors $(n \geq 5)$, and predictors shown to be significant $(p \leq 0.05)$ by at least two studies

\begin{tabular}{|c|c|c|c|c|}
\hline Predictors $(n)$ & $\begin{array}{c}\text { Significant }(+) \text { association }^{a} \\
(p \leq 0.05)\end{array}$ & $\begin{array}{c}\text { Significant } \\
\text { association } \\
(p \leq 0.05) ; \\
\text { direction } \\
\text { unspecified or } \\
\text { inconsistent }\end{array}$ & $\begin{array}{l}\text { Significant }(-) \\
\text { association }^{\mathrm{a}} \\
(p \leq 0.05)\end{array}$ & No significant association or association not reported \\
\hline $\begin{array}{l}\text { Sociodemographic characteristics } \\
\text { Younger age }(n=27) \\
\text { Non-Caucasian ethnicity }(n=11) \\
\text { Unmarried }(n=23) \\
\text { Lower education }(n=21) \\
\text { Lower income }(n=7) \\
\text { Financial difficulties }(n=6) \\
\text { Unemployment }(n=9) \\
\end{array}$ & $\begin{array}{l}{[10][11][\mathbf{1 5}][20][\mathbf{2 2}][23][32][\mathbf{3 7}][38][49]} \\
{[16][20]} \\
{[10][\mathbf{1 2}][18][\mathbf{2 2}][31][\mathbf{3 6}][\mathbf{3 7}][41]} \\
{[10][14][\mathbf{1 5}]} \\
{[\mathbf{1 2}][\mathbf{1 4}][\mathbf{2 2}][33]} \\
{[18][20][32][\mathbf{3 5}][43]} \\
{[40]}\end{array}$ & $\begin{array}{l}{[19][33]} \\
{[23][47]} \\
{[11][33][38][48]} \\
{[12]} \\
\\
{[23]}\end{array}$ & [42] & $\begin{array}{l}{[12][14][16][18][21][30][31][35][39][40][41][44][45][48]} \\
{[10][11][25][38][40][41][49]} \\
{[14][16][19][20][23][30][32][35][40][45][49]} \\
{[11][16][18][19][20][22][23][30][31][32][33][35][38][39][41][42][48]} \\
{[23][35][41]} \\
{[38]} \\
{[14][16][22][31][33][35][38]}\end{array}$ \\
\hline $\begin{array}{l}\text { Breast cancer characteristics and treatment } \\
\text { More advanced breast cancer at diagnosis }(n=21) \\
\text { Mastectomy }(n=19) \\
\text { Treatment with chemotherapy }(n=18) \\
\text { Treatment with radiotherapy }(n=15) \\
\text { Treatment with hormone therapy }(n=17) \\
\text { Longer primary treatment duration }(n=2) \\
\text { More recent transition into survivorship }(n=10) \\
\text { Breast cancer recurrence }(n=4)\end{array}$ & $\begin{array}{l}{[\mathbf{1 5}][20][31]} \\
{[50]} \\
{[18][19][20][31]} \\
{[23][43]} \\
{[22][32][38]} \\
{[22][31]}\end{array}$ & $\begin{array}{l}{[14]} \\
{[14]} \\
{[10][16]}\end{array}$ & $\begin{array}{l}{[11]} \\
{[12]} \\
{[20]} \\
{[38]}\end{array}$ & $\begin{array}{l}[10][12][14][18][22][23][32][33][35][36][37][39][41]][42][45][48][50] \\
{[10][11][12][18][20][22][23][30][31][33][35][39][40][41][42][45][48]} \\
{[10][11][12][14][16][22][23][30][33][35][37][39][40][48]} \\
{[10][11][16][18][19][20][22][23][30][33][35][39][40]} \\
{[11][12][14][18][19][23][30][33][35][37][39][40][41][45]} \\
{[10][14][15][30][40][43][45]} \\
{[32]}\end{array}$ \\
\hline $\begin{array}{l}\text { Treatment-related symptoms } \\
\text { Menopausal/vasomotor symptoms }(n=10) \\
\text { Pain }(n=12) \\
\text { Fatigue }(n=9) \\
\text { Sleep disturbance/insomnia }(n=9) \\
\text { Lymphedema/arm symptoms }(n=5) \\
\text { Breast symptoms }(n=3) \\
\text { Appetite loss }(n=5) \\
\text { Diarrhea }(n=5) \\
\text { Dyspnea }(n=4) \\
\text { Constipation }(n=5) \\
\text { Nausea and vomiting }(n=5) \\
\text { Higher number of treatment-related complaints }(n=5)\end{array}$ & $\begin{array}{l}{[10][12][14][20][35][40][42]} \\
{[10][12][14][16][20][32][38][43][48]} \\
{[12][20][30][3][32][43]} \\
{[10][14][27][30][32][40][43]} \\
{[\mathbf{1 4}][43]} \\
{[14][43]} \\
{[\mathbf{1 4}][32]} \\
{[14][32][43]} \\
{[\mathbf{1 4}][32]} \\
{[\mathbf{1 4}]} \\
{[32]} \\
{[39][43][46]}\end{array}$ & $\begin{array}{l}{[48]} \\
{[11]}\end{array}$ & & $\begin{array}{l}{[11][41][45]} \\
{[31][35][45]} \\
{[35][38]} \\
{[35][38]} \\
{[35][45]} \\
{[35]} \\
{[35][38][43]} \\
{[35][38]} \\
{[38][43]} \\
{[32][35][38][43]} \\
{[14][35][38][43]} \\
{[35][45]}\end{array}$ \\
\hline $\begin{array}{l}\text { Comorbidities and medical history } \\
\text { Higher number of comorbidities }(n=9) \\
\text { History of mental health problems }(n=7)\end{array}$ & $\begin{array}{l}{[11][\mathbf{1 2}][\mathbf{2 3}][30][33]} \\
{[\mathbf{1 9} \mid[\mathbf{2 2}][31][\mathbf{3 7}][41][42][50]}\end{array}$ & [16] & & {$[31][35][41]$} \\
\hline $\begin{array}{l}\text { Perceived functioning limitations } \\
\text { Lower quality of life/global health status }(n=8) \\
\text { Lower quality of physical health }(n=4) \\
\text { Lower quality of mental health }(n=2) \\
\text { Physical functioning limitations }(n=8) \\
\text { Role functioning limitations }(n=8) \\
\text { Emotional functioning limitations }(n=5) \\
\text { Cognitive functioning limitations }(n=4) \\
\text { Social functioning limitations }(n=6) \\
\text { Lower optimism (n }=3 \text { ) } \\
\text { Lower posttraumatic growth }(n=3) \\
\text { Higher number of stressful life events }(n=6)\end{array}$ & $\begin{array}{l}{[12][14][18][29][32][43]} \\
{[12][30][31][33]} \\
{[\mathbf{1 2}][30]} \\
{[10][12][18][32][38][43]} \\
{[12][18][32][33][\mathbf{3 5}][43]} \\
{[12][32][43]} \\
{[32][43]} \\
{[12][32][33][43]} \\
{[10][29]} \\
{[28][\mathbf{3 6}][46]} \\
{[10][\mathbf{1 9}][31]}\end{array}$ & {$[37][38 \mid[50]$} & & $\begin{array}{l}{[35][38]} \\
\\
{[16][35]} \\
{[35][38]} \\
{[35][38]} \\
{[35][38]} \\
{[35][38]} \\
{[39]}\end{array}$ \\
\hline $\begin{array}{l}\text { Behavioral and support factors } \\
\quad \text { Lower physical activity }(n=8) \\
\text { Lower social support }(n=8) \\
\text { Cigarette smoking }(n=6) \\
\text { Higher alcohol intake }(n=5) \\
\text { Higher BMI }(n=7)\end{array}$ & $\begin{array}{l}{[10][11][13][17][25]} \\
{[10][15][33][36][38][46]} \\
{[10][11]} \\
{[10]}\end{array}$ & $\begin{array}{l}{[35]} \\
{[11]}\end{array}$ & & $\begin{array}{l}{[16][30][35]} \\
{[20]} \\
{[13][16][30][35]} \\
{[10][13][16][35][50]} \\
{[16][31][35][40][41]}\end{array}$ \\
\hline
\end{tabular}

distress. For behavioral and support factors, lower physical activity, lower social support, and cigarette smoking were associated with distress. Informed by this systematic review, risk stratification may be a viable approach to identify women at higher risk of developing distress following completion of primary breast cancer treatment to provide targeted evidence-based interventions.

Breast cancer-specific factors were commonly evaluated as candidate predictors, given that conventional wisdom suggests that recent, traumatic experiences, such as advanced breast cancer diagnosis associated with worse prognosis and increased risk of premature mortality or more aggressive anti-cancer therapy, may increase the risk of distress. The systematic review identified initial diagnosis of more advanced breast cancer, treatment with chemotherapy, and longer primary treatment duration as predictors of distress. It is difficult to disentangle these predictors, given that they are highly correlated; women with more advanced breast cancer will undergo more aggressive anti-cancer treatment including chemotherapy, which in turn will substantially increase treatment duration. However, a potential underlying mechanism for increased distress in survivorship is that women diagnosed with more advanced breast cancer associated with higher risk of recurrence may experience more intense fears of recurrence [52], which if unmanaged could progress to diagnosable mental health problems. One study included in this systematic review reported significant univariate associations for both breast cancer stage and treatment with chemotherapy with distress; however, only more advanced breast cancer was significant in the multivariate model [31]. Furthermore, the systematic review showed that other forms of anti-cancer therapy (i.e., type of surgery, treatment with radiotherapy, or treatment with hormone 
therapy) did not influence the risk of distress. These findings are supported by two large Danish cohort studies that evaluated predictors of distress following breast cancer diagnosis and identified number of tumor-positive axillary lymph nodes as an independent predictor of new antidepressant use [53, 54]. Although both studies evaluated breast cancer-related treatments as candidate predictors of distress, neither found independent associations for mastectomy, chemotherapy, or radiotherapy. The results of this systematic review suggest that more advanced breast cancer, as well as its correlates could help to identify women at higher risk of experiencing distress in survivorship.

The review identified potentially modifiable breast cancer treatment-related risk factors. Timely identification and effective management of treatment-related symptoms could serve as a possible intervention to prevent distress or mitigate its effects. Symptoms commonly associated with anti-cancer therapy were predominantly assessed using standardized cancer-specific measures of health-related quality of life as well as breast cancer-specific measures $[55,56]$. Other treatment-related symptoms not captured by this systematic review may also be associated with distress. Identification of additional relevant symptoms should be guided through clinical expertise and investigated to assess the relationship with distress. These findings suggest that it may not be anti-cancer therapy that directly affects distress, but rather adverse events resulting from treatment that increase the risk of distress. Uncontrolled chronic and latent treatment-related symptoms can negatively affect health-related quality of life in survivorship and may serve as consistent reminders of the breast cancer diagnosis increasing fear of recurrence $[52,57]$. Further studies are needed to assess independent contributions of more advanced breast cancer, treatments, and associated side effects on distress in survivorship.

Additional risk factors not directly related to diagnosis or treatment of breast cancer, including sociodemographic characteristics, comorbidities, medical history, and functional limitations, have also been shown to increase the risk of distress in the general population. In fact, many of these risk factors have been incorporated into predictive algorithms to estimate risk of incident distress in general practice [58-61]. Each of the algorithms includes younger age, indicator(s) of lower SES, and indicator(s) of perceived functioning limitations as predictors. In addition, some algorithms include comorbidities, history of mental health problems, and experiences of discrimination (e.g., racial discrimination [60]). Although this may seem intuitive, the results of this systematic review indicate that risk factors for distress in the general population can also be useful in identifying breast cancer patients at higher risk of distress following completion of primary treatment. Effectively, these risk factors make breast cancer survivors inherently more susceptible to development of distress when faced with challenges in survivorship. However, it is unclear whether or not these factors have differential effects in breast cancer survivors. For example, younger survivors may have different expectations of a normal fulfilling life and experience substantially higher distress as a function of receiving a premature life-threatening diagnosis, as well as coping with potential implications when raising young children. Future studies should focus on identifying interactions between risk factors in the general population and diagnosis of breast cancer in predicting distress.

The review also highlighted modifiable behavior and support factors that could serve as interventions to prevent or mitigate the impact of distress. As expected, lower physical activity, lower social support, and cigarette smoking were associated with the presence of distress [62-64]. In fact, lifestyle and support programs that develop and promote positive coping strategies have been shown to reduce distress symptoms in breast cancer survivors [65-68]. However, contrary to results from prior studies in the general population [69, 70], alcohol intake and BMI did not influence the risk of distress. None of the studies that evaluated alcohol intake showed a significant association. There were low prevalences and absolute numbers of women who reported higher alcohol intake in these studies [10, 13, 35, 50]. Given that higher alcohol intake has been shown to increase risk of breast cancer recurrence [71], this may reflect changes in alcohol consumption due to personal choice or medical advice following breast cancer diagnosis. For studies that reported no association between BMI and distress, three studies compared mean BMI between distressed and non-distressed women, and may have been underpowered to detect significant differences due to lower sample sizes [31, 40, 41]. Another study reported a low prevalence of increased BMI from $<25$ to $\geq 25$ with a very low number of distressed women transitioning to increased BMI [35]. Future research should focus on exploring these associations in more depth.

This systematic review highlighted an important research gap; no studies evaluated predictors of incident distress in breast cancer survivors. Instead, studies assessed candidate predictors of prevalent distress making it unclear whether the 'predictor' or distress occurred first and introducing the possibility of reverse causation. In order to advance this field, future research should focus on establishing predictors of incident distress in breast cancer survivors with no concurrent or recent history of distress. Ideally, a large cohort of breast cancer survivors should be prospectively followed for incident distress, and evidencebased as well as clinically informed candidate predictors should be evaluated using time-to-event analysis. 
Furthermore, harmonization of vocabulary around distress and survivorship periods would aid future research to develop more explicit recommendations. First, the nonspecific nature of distress makes it difficult to describe and measure. Furthermore, levels and predictors of distress are expected to change across the breast cancer survivorship life course; women who have recently transitioned into survivorship have different concerns and priorities compared to longer-term survivors. Future research should focus on predictors of distress for different intervals of the survivorship period, e.g., transitional survivorship (first year following completion of primary treatment), shortterm survivorship (2-5 years after completion of primary treatment), and long-term survivorship ( $>5$ years after completion of primary treatment).

This study has several limitations resulting from the quality and scope of articles identified through the systematic review. Publication bias and inter-study heterogeneity limited the feasibility of conducting predictorspecific meta-analyses. The majority of studies only reported measures of association for significant predictors, which would have biased pooled estimates toward significance. Furthermore, studies that evaluated the same candidate predictor often used different measurements and classification approaches, making predictor-specific metaanalyses impossible. However, the synthesis conducted for this systematic review allowed for direct comparison of significant impact of predictors between studies assessing the same predictor.

This systematic review has established a set of evidencebased predictors that can be used to identify women at higher risk of experiencing distress following completion of primary breast cancer treatment. More advanced breast cancer and treatment-related symptoms may serve as the most practical predictors of distress in survivorship. Furthermore, findings suggest that risk factors for distress in the general population can also be used in this vulnerable population; this intuitively makes sense, given that women predisposed to distress are more likely to experience increased levels as a result of a life-altering breast cancer diagnosis. This systematic review provides preliminary evidence to address an important clinical gap. Furthermore, the results can serve to inform development of a risk stratification algorithm to identify women at higher risk of developing distress following completion of primary breast cancer treatment to provide appropriate support to prevent distress or mitigate its effects.

Acknowledgements The authors would like to thank Genevieve Gore for assistance in developing the systematic review search strategies. While conducting this study, AS was supported by the Canadian Institutes of Health Research (CIHR) through the Frederick Banting and Charles Best Canada Graduate Scholarship Doctoral Research Award.

\section{Compliance with ethical standards}

Conflict of interest The authors declare that they have no conflict of interest.

Ethical approval This article does not contain any studies with human participants or animals performed by any of the authors.

Open Access This article is distributed under the terms of the Creative Commons Attribution 4.0 International License (http://crea tivecommons.org/licenses/by/4.0/), which permits unrestricted use, distribution, and reproduction in any medium, provided you give appropriate credit to the original author(s) and the source, provide a link to the Creative Commons license, and indicate if changes were made.

\section{References}

1. Ferlay J, Soerjomataram I, Ervik M, Dikshit R, Eser S, Mathers C, Rebelo M, Parkin DM, Forman D, Bray F (2013) GLOBOCAN 2012: estimated cancer incidence, mortality and prevalence worldwide in 2012, v1.2. International Agency for Research on Cancer, Lyon. http://globocan.iarc.fr/Pages/fact_sheets_cancer. aspx. Accessed 27 Nov 2016

2. Laronga C (2016) Patient education: breast cancer guide to diagnosis and treatment (beyond the basics). In: Post TW (ed), UpToDate. UpToDate, Waltham. https://www.uptodate.com/con tents/breast-cancer-guide-to-diagnosis-and-treatment-beyond-thebasics. Accessed 7 Dec 2016

3. Canadian Cancer Society's Advisory Committee on Cancer Statistics (2016) Canadian Cancer Statistics 2016. Canadian Cancer Society, Toronto. http://www.cancer.ca/ /media/cancer. $\mathrm{ca} / \mathrm{CW} /$ cancer\%20information/cancer\%20101/Canadian\%20can cer\%20statistics/Canadian-Cancer-Statistics-2016-EN.pdf?la=en. Accessed 20 Dec 2016

4. Holland JC, Jacobsen PB, Andersen B et al. (2016) NCCN clinical practice guidelines in oncology: distress management, v2.2016. National Comprehensive Cancer Network, Inc. https:// www.nccn.org/professionals/physician_gls/pdf/distress.pdf. Accessed 8 May 2016

5. Adler NE, Page AEK (eds) (2008) Cancer care for the whole patient: meeting psychosocial health needs. The National Academies Press, Washington DC

6. Grunfeld E, Hodgson DC, Del Giudice ME, Moineddin R (2010) Population-based longitudinal study of follow-up care for breast cancer survivors. J Oncol Pract 6:174-181. doi:10.1200/JOP. 200009

7. Pitceathly C, Maguire P, Fletcher I, Parle M, Tomemson B, Creed F (2009) Can a brief psychological intervention prevent anxiety or depressive disorders in cancer patients? A randomised controlled trial. Ann Oncol 20:928-934. doi:10.1093/annonc/ $\operatorname{mdn} 708$

8. Landis JR, Koch GG (1977) The measurement of observer agreement for categorical data. Biometrics 33:159-174. doi:10. $2307 / 2529310$

9. Moher D, Liberati A, Tetzlaff J, Altman DG, PRISMA Group (2009) Preferred reporting items for systematic reviews and metaanalyses: the PRISMA statement. Ann Intern Med 151:264-269. doi:10.7326/0003-4819-151-4-200908180-00135

10. Bardwell WA, Natarajan L, Dimsdale JE, Rock CL, Mortimer JE, Hollenbach K, Pierce JP (2006) Objective cancer-related variables are not associated with depressive symptoms in women 
treated for early-stage breast cancer. J Clin Oncol 24:2420-2427. doi:10.1200/JCO.2005.02.0081

11. Dominick SA, Natarajan L, Pierce JP, Madanat H, Madlensky L (2014) The psychosocial impact of lymphedema-related distress among breast cancer survivors in the WHEL study. Psychooncology 23:1049-1056. doi:10.1002/pon.3510

12. Chen X, Zheng Y, Zheng W, Gu K, Chen Z, Lu W, Shu XO (2009) Prevalence of depression and its related factors among Chinese women with breast cancer. Acta Oncol 48:1128-1136. doi:10.3109/02841860903188650

13. Chen X, Lu W, Zheng Y, Gu K, Chen Z, Zheng W, Sho XO (2010) Exercise, tea consumption, and depression among breast cancer survivors. J Clin Oncol 28:991-998. doi:10.1200/JCO. 2009.23.0565

14. Kim SH, Son BH, Hwang SY, Han W, Yang J, Lee S, Yun YH (2008) Fatigue and depression in disease-free breast cancer survivors: prevalence, correlates, and association with quality of life. J Pain Symptom Manag 35:644-655. doi:10.1016/j.jpainsymman. 2007.08.012

15. Mehnert A, Koch U (2008) Psychological comorbidity and health-related quality of life and its association with awareness, utilization, and need for psychosocial support in a cancer registerbased sample of long-term breast cancer survivors. J Psychosom Res 64:383-391. doi:10.1016/j.jpsychores.2007.12.005

16. Calhoun C, Helzlsouer KJ, Gallicchio L (2015) Racial differences in depressive symptoms and self-rated health among breast cancer survivors on aromatase inhibitor therapy. J Psychosoc Oncol 33:263-277. doi:10.1080/07347332.2015.1019661

17. Bränström R, Petersson L-M, Saboonchi F, Wennman-Larsen A, Alexanderson K (2015) Physical activity following a breast cancer diagnosis: implications for self-rated health and cancerrelated symptoms. Eur J Oncol Nurs 19:680-685. doi:10.1016/j. ejon.2015.04.008

18. Saboonchi F, Petersson L-M, Wennman-Larsen A, Alexanderson K, Vaez M (2015) Trajectories of anxiety among women with breast cancer: a proxy for adjustment from acute to transitional survivorship. J Psychosoc Oncol 33:603-619. doi:10.1080/ 07347332.2015.1082165

19. Saboonchi F, Petersson L-M, Wennman-Larsen A, Alexanderson K, Brännström R, Vaez M (2014) Changes in caseness of anxiety and depression in breast cancer patients during the first year following surgery: patterns of transiency and severity of the distress response. Eur J Oncol Nurs 18:598-604. doi:10.1016/j. ejon.2014.06.007

20. Avis NE, Levine BJ, Case LD, Naftalis EZ, Van Zee KJ (2015) Trajectories of depressive symptoms following breast cancer diagnosis. Cancer Epidemiol Biomark Prev 24:1789-1795. doi:10.1158/1055-9965.EPI-15-0327

21. Ganz PA, Greendale GA, Petersen L, Kahn B, Bower JE (2003) Breast cancer in younger women: reproductive and late health effects of treatment. J Clin Oncol 21:4184-4193. doi:10.1200/ JCO.2003.04.196

22. Qiu J, Yang M, Chen W, Gao X, Liu S, Shi S, Xie B (2012) Prevalence and correlates of major depressive disorder in breast cancer survivors in Shanghai, China. Psychooncology 21:1331-1337. doi:10.1002/pon.2075

23. Stanton AL, Wiley JF, Krull JL, Crespi CM, Hammen C, Allen JJB, Barron ML, Jorge A, Weihs KL (2015) Depressive episodes, symptoms, and trajectories in women recently diagnosed with breast cancer. Breast Cancer Res Treat 154:105-115. doi:10. 1007/s10549-015-3563-4

24. Boehmer U, Glickman M, Winter M (2012) Anxiety and depression in breast cancer survivors of different sexual orientations. J Consult Clin Psychol 80:382-395. doi:10.1037/a0027494

25. Kim BH, Dash C, Gomez SL, Sheppard VB, Allen L, Wang Y, Wang JH (2013) Associations of physical activity with physical functioning and emotional distress among non-Hispanic white and Chinese-American breast cancer survivors [abstract]. In: Proceedings of the twelfth annual AACR international conference on frontiers in cancer prevention research; 2013 Oct 27-30; National Harbor. Cancer Prev Res 6:B21. doi: 10.1158/19406215.PREV-13-B21

26. Hong C-C, Yao S, Zhang Y, Kumar S, Ambrosone C (2015) High serum levels of 25-hydroxyvitamin $\mathrm{D}$ are associated with better quality-of-life, and lower levels of perceived stress, depression, and fatigue among breast cancer survivors [abstract]. In: Proceedings of the thirty-seventh annual CTRC-AACR San Antonio breast cancer symposium: 2014 Dec 9-13; San Antonio. Cancer Res 75:P1-09-27. doi:10.1158/1538-7445.SABCS14-P1-09-27

27. Palesh O, Mustian K, Peppone L, Sprod L, Spiegel D, Morrow G (2010) Sleep disturbance predicts mood and anxiety disorders in breast cancer and prostate cancer survivors over a 3-months follow up: a urcc ccop study ( $\mathrm{N}=662)$ [abstract]. In: Abstracts of the 2010 international MASCC/ISOO symposium; 2010 June 24-26; Vancouver. Support Care Cancer 18:19-221(S185-6). doi: 10.1007/s00520-010-0891-0

28. Wang AW-T (2015) A dual-trajectory model of post-traumatic growth and depression among breast cancer patients [abstract]. In: Abstracts of the 2015 world congress of psych-oncology; 2015 July 28-Aug 1; Washington, DC. Psychooncology 24:P1-24(116). doi: 10.1002/pon.3874

29. Leung J, Atherton I, Kyle RG, Hubbard G, McLaughlin D (2016) Psychological distress, optimism and general health in breast cancer survivors: a data linkage study using the Scottish health survey. Support Care Cancer 24:1755-1761. doi:10.1007/s00520015-2968-2

30. Romito F, Cormio C, Giotta F, Colucci G, Mattioli V (2012) Quality of life, fatigue and depression in Italian long-term breast cancer survivors. Support Care Cancer 20:2941-2948. doi:10. 1007/s00520-012-1424-9

31. Kim J-M, Jang J-E, Stewart R, Kim S-Y, Kim S-W, Kang H-J, Shin I-S, Park M-H, Yoon J-H, Yoon J-S (2013) Determinants of suicidal ideation in patients with breast cancer. Psychooncology 22:2848-2856. doi:10.1002/pon.3367

32. Reyes-Gibby CC, Anderson KO, Morrow PK, Shete S, Hassan S (2012) Depressive symptoms and health-related quality of life in breast cancer survivors. J Women's Health 21:311-318. doi:10. 1089/jwh.2011.2852

33. Ashing-Giwa K, Rosales M, Lai L, Weitzel J (2013) Depressive symptomatology among Latina breast cancer survivors. Psychooncology 22:845-853. doi:10.1002/pon.3084

34. Wang GL, Shih S-M, Hsu S-H, Hou Y-C, Feng A-C, Cheng C-T (2011) Physical problems and psychosocial distress in breast cancer survivors [abstract]. In: Abstracts of the IPOS 13th world congress of psycho-oncology; 2011 Oct 16-20; Antalya. Psychooncology 20:P2-112(225). doi: 10.1002/pon.2078

35. Lee MK, Park S, Lee ES, Ro J, Kang HS, Shin KH, Lee KS, Chung KW, Kim SW, Yun YH (2011) Social support and depressive mood 1 year after diagnosis of breast cancer compared with the general female population: a prospective cohort study. Support Care Cancer 19:1379-1392. doi:10.1007/s00520-0100960-4

36. Hsu SH, Shih S-M, Feng A-C, Wang G-L, Hou Y-C, Chen S-H, Cheng C-T (2010) Factors associated with psychological distress in early breast cancer survivors in Taiwan [abstract]. In: Abstracts of the IPOS 12th world congress of psycho-oncology; 2010 May 25-29; Quebec City. Psychooncology 19:P-136(S207-8). doi: 10. 1002/pon. 1776

37. Burgess C, Cornelius V, Love S, Graham J, Richards M, Ramirez A (2005) Depression and anxiety in women with early breast cancer: five year observational cohort study. BMJ 330:702-705. doi:10.1136/bmj.38343.670868.D3 
38. Kornblith AB, Herndon JE, Zuckerman E, Viscoli CM, Horowitz RI, Cooper MR, Harris L, Tkaczuk KH, Perry MC, Budman D, Norton L, Holland JC, Cancer and Leukemia Group B (2001) Social support as a buffer to the psychological impact of stressful life events in women with breast cancer. Cancer 91:443-454. doi:10.1002/1097-0142(20010115)91:2<443:AID-

CNCR1020>3.0.CO;2-Z

39. Henselmans I, Helgeson VS, Seltman H, de Vries J, Sanderman R, Ranchor AV (2010) Identification and prediction of distress trajectories in the first year after a breast cancer diagnosis. Health Psychol 29:160-168. doi:10.1037/a0017806

40. Accortt EE, Bower JE, Stanton AL, Ganz PA (2015) Depression and vasomotor symptoms in young breast cancer survivors: the mediating role of sleep disturbance. Arch Womens Mental Health 18:565-568. doi:10.1007/s00737-015-0504-5

41. Donovan KA, Gonzalez BD, Small BJ, Andrykowski MA, Jacobsen PB (2014) Depressive symptom trajectories during and after adjuvant treatment for breast cancer. Ann Behav Med 47:292-302. doi:10.1007/s12160-013-9550-2

42. Morasso G, Costantini M, Viterbori P, Bonci F, Mastro LD, Musso M, Garrone O, Venturini M (2001) Predicting mood disorders in breast cancer patients. Eur J Cancer 37:216-223. doi:10. 1016/S0959-8049(00)00390-7

43. Ploos van Amstel FK, van den Berg SW, van Laarhoven HWM, Gielissen MFM, Prins JB, Ottevanger PB (2013) Distress screening remains important during follow-up after primary breast cancer treatment. Support Care Cancer 21:2107-2115. doi:10.1007/s00520-013-1764-0

44. Kornblith AB, Powell M, Regan MM, Bennett S, Krasner C, Moy B, Younger J, Goodman A, Berlowitz R, Winer E (2007) Longterm psychosocial adjustment of older vs younger survivors of breast and endometrial cancer. Psychooncology 16:895-903. doi:10.1002/pon.1146

45. Brunault P, Suzanne I, Trzepidur-Edom M, Garaud P, Calais G, Toledano A, Camus V (2013) Depression is associated with some patient-perceived cosmetic changes, but not with radiotherapyinduced late toxicity, in long-term breast cancer survivors. Psychooncology 22:590-597. doi:10.1002/pon.3038

46. Wang GL, Shih S-M, Hou Y-C, Hsu S-H, Feng A-C, Cheng C-T (2013) Trajectories of psychosocial distress and its correlation with physical problems, social support, coping styles and posttraumatic growth among breast cancer survivors [abstract]. In: Abstracts of the IPOS 15th world congress of psycho-oncology; 2013 Nov 4-8; Rotterdam. Psychooncology 22:P3-48(308). doi:10.10002/pon.3394

47. Eversley R, Estrin D, Dibble S, Wardlaw L, Pedrosa M, FavilaPenney W (2005) Post-treatment symptoms among ethnic minority breast cancer survivors. Oncol Nurs Forum 32:250-256. doi:10.1188/05.ONF.250-256

48. Vahdaninia M, Omidvari S, Montazeri A (2010) What do predict anxiety and depression in breast cancer patients? a follow-up study. Soc Psychiatr Epidemiol 45:355-361. doi:10.1007/s00127009-0068-7

49. Neerukonda AR, Stevens MM, Reagan L, Cohen J, Baer LN, Messina C, Nemesure B (2015) Assessment of distress among breast cancer survivors [abstract]. In: Proceedings of the 2015 American society of clinical oncology annual meeting: 2015 May 29-June 2; Chicago. J Clin Oncol 33:e12610

50. Shelby RA, Golden-Kreutz DM, Andersen BL (2008) PTSD diagnoses, subsyndromal symptoms, and comorbidities contribute to impairments for breast cancer survivors. J Trauma Stress 21:165-172. doi:10.1002/jts.20316

51. Baider L, Goldzweig G, Ever-Hadani P, Peretz T (2008) Breast cancer and psychological distress: mothers' and daughters' traumatic experiences. Support Care Cancer 16:407-414. doi:10. 1007/s00520-007-0320-1
52. Liu Y, Perez M, Schootman M, Aft RL, Gillanders WE, Jeffe DB (2011) Correlates of fear of cancer recurrence in women with ductal carcinoma in situ and early invasive breast cancer. Breast Cancer Res Treat 130:165-173. doi:10.1007/s10549-011-1551-x

53. Suppli NP, Deltour I, Damkjær LH, Christensen J, Jensen AB, Kroman AT, Johansen C, Dalton SO (2011) Factors associated with the prescription of antidepressive medication to breast cancer patients. Acta Oncol 50:243-251. doi:10.3109/0284186X. 2010.531049

54. Suppli NP, Johansen C, Christensen J, Kessing LV, Kroman N, Dalton SO (2014) Increased risk for depression after breast cancer: a nationwide population-based cohort study of associated factors in Denmark, 1998-2011. J Clin Oncol 32:3831-3839. doi:10.1200/JCO.2013.54.0419

55. Aaronson NK, Ahmedzai S, Bergman B, Bullinger M, Cull A, Duez NJ, Filiberti A, Flechtner H, Fleishman SB, de Haes JCJM, Kaasa S, Klee M, Osoba D, Razavi D, Rofe PB, Schraub S, Sneeuw K, Sullivan M, Takeda F, European Organization for Research and Treatment of Cancer Study Group on Quality of Life (2005) The European organization for research and treatment of cancer QLQ-C30: a quality-of-life instrument for use in international clinical trials in oncology. J Natl Cancer Inst 85:365-376. doi:10.1093/jnci/85.5.365

56. Sprangers MA, Groenvold M, Arraras JI, Franklin J, te Velde A, Muller M, Franzini L, Williams A, de Haes HC, Hopwood P, Cull A, Aaronson NK (1996) The European organization for research and treatment of cancer breast cancer-specific quality-of-life questionnaire module: first results from a three-country field study. J Clin Oncol 14:2756-2768. doi:10.1200/JCO.1996.14.10. 2756

57. Janz NK, Mujahid M, Chung LK, Lantz PM, Hawley ST, Morrow M, Schwartz K, Katz SJ (2007) Symptom experience and quality of life of women following breast cancer treatment. J Womens Health (Larchmt) 16:1348-1361. doi:10.1089/jwh.2006.0255

58. King M, Walker C, Levy G, Bottomley C, Royston P, Weich S, Bellón-Saameño JA, Moreno B, Svab I, Rotar D, Rifel J, Maaroos HI, Aluoja A, Kalda R, Neeleman J, Geerlings MI, Xavier M, Carraça I, Gonçalves-Pereira M, Vicente B, Saldivia S, Melipillan R, Torres-Gonzalez F, Nazareth I (2008) Development and validation of an international risk prediction algorithm for episodes of major depression in general practice attendees: the PredictD study. Arch Gen Psychiatry 65:1368-1376. doi:10. 1001/archpsyc.65.12.1368

59. Wang JL, Manuel D, Williams J, Schmitz N, Gilmour H, Patten S, MacQueen G, Birney A (2013) Development and validation of prediction algorithms for major depressive episode in the general population. J Affect Disord 151:39-45. doi:10.1016/j.jad.2013. 05.045

60. Wang J, Sareen J, Patten S, Bolton J, Schmitz N, Birney A (2014) A prediction algorithm for first onset of major depression in the general population: development and validation. J Epidemiol Community Health 68:418-424. doi:10.1136/jech-2013-202845

61. Moreno-Peral P, de Dios Luna J, Marston L, King M, Nazareth I, Motrico E, GildeGómez-Barragán MJ, Torres-González F, Montón-Franco C, Sánchez-Celaya M, Díaz-Barreiros MÁ, Vicens C, Muñoz-Bravo C, Bellón JÁ (2014) Predicting the onset of anxiety syndromes at 12 months in primary care attendees. The PredictA-Spain study. PLoS ONE 9:e106370. doi:10.1371/ journal.pone.0106370.t007

62. Mammen G, Faulkner G (2013) Physical activity and the prevention of depression: a systematic review of prospective studies. Am J Prev Med 45:649-657. doi:10.1016/j.amepre.2013.08.001

63. Moylan S, Jacka FN, Pasco JA, Berk M (2012) Cigarette smoking, nicotine dependence and anxiety disorders: a systematic review of population-based, epidemiological studies. BMC Med 10:123. doi:10.1186/1741-7015-10-123 
64. Ozbay F, Johnson DC, Dimoulas E, Morgan CA, Charney D, Southwick S (2007) Social support and resilience to stress: from neurobiology to clinical practice. Psychiatry (Edgmont) 4:35-40

65. Zhu G, Zhang X, Wang Y, Xiong H, Zhao Y, Sun F (2016) Effects of exercise intervention in breast cancer survivors: a meta-analysis of 33 randomized controlled trails. Onco Targets Ther 9:2153-2168. doi:10.2147/OTT.S97864

66. Mens MG, Helgeson VS, Lembersky BC, Baum A, Scheier MF (2016) Randomized psychosocial interventions for breast cancer: impact on life purpose. Psychooncology 25:618-625. doi:10. 1002/pon.3891

67. Badr H, Krebs P (2013) A systematic review and meta-analysis of psychosocial interventions for couples coping with cancer. Psychooncology 22:1688-1704. doi:10.1002/pon.3200

68. Taylor G, McNeill A, Girling A, Farley A, Lindson-Hawley N, Aveyard P (2014) Change in mental health after smoking cessation: systematic review and meta-analysis. BMJ 348:g1151. doi:10.1136/bmj.g1151

69. Luppino FS, de Wit LM, Bouvy PF, Stijnen T, Cuijpers P, Penninx BW, Zitman FG (2010) Overweight, obesity, and depression: a systematic review and meta-analysis of longitudinal studies. Arch Gen Psychiatry 67:220-229. doi:10.1001/arch genpsychiatry.2010.2

70. Boden JM, Fergusson DM (2011) Alcohol and depression. Addiction 106:906-914. doi:10.1111/j.1360-0443.2010.03351.x

71. Kwan ML, Kushi LH, Weltzien E, Tam EK, Castillo A, Sweeney C, Caan BJ (2010) Alcohol consumption and breast cancer recurrence and survival among women with early-stage breast cancer: the life after cancer epidemiology study. J Clin Oncol 28:4410-4416. doi:10.1200/JCO.2010.29.2730 